\title{
IL-11 separates graft-versus-leukemia effects from graft-versus-host disease after bone marrow transplantation
}

\author{
Takanori Teshima, ${ }^{1}$ Geoffrey R. Hill, ${ }^{2}$ Luying Pan, ${ }^{2}$ Yani S. Brinson, ${ }^{2}$ \\ Marcel R.M. van den Brink, ${ }^{2,3}$ Kenneth R. Cooke, ${ }^{2}$ and James L.M. Ferrara ${ }^{1}$ \\ ${ }^{1}$ Departments of Internal Medicine and Pediatrics, University of Michigan Cancer Center, \\ Ann Arbor, Michigan 48109-0942, USA \\ ${ }^{2}$ Department of Pediatric Oncology, Dana Farber Cancer Institute, Harvard Medical School, \\ Boston, Massachusetts 02115, USA \\ ${ }^{3}$ Department of Hematology/Oncology, Beth Israel Deaconess Medical Center, Boston, Massachusetts 02215, USA
}

Address correspondence to: James L.M. Ferrara, Bone Marrow Transplantation Program,

University of Michigan Cancer Center, 1500 East Medical Center Drive, Ann Arbor, Michigan 48109-0942, USA.

Phone: (734) 615-1340; Fax: (734) 647-9271; E-mail: ferrara@umich.edu.

Received for publication April 16, 1999, and accepted in revised form June 18, 1999. We recently showed that IL-11 prevents lethal graft-versus-host disease (GVHD) in a murine bone
marrow transplantation (BMT) model of GVHD directed against MHC and minor antigens. In this
study, we have investigated whether IL-11 can maintain a graft-versus-leukemia (GVL) effect. Lethal-
ly irradiated B6D2F1 mice were transplanted with either T cell-depleted (TCD) bone marrow (BM)
alone or with BM and splenic T cells from allogeneic B6 donors. Animals also received host-type P815
mastocytoma cells at the time of BMT. Recipients were injected subcutaneously with recombinant
human IL-11 or control diluent twice daily, from 2 days before BMT to 7 days after BMT. TCD recip-
ients all died from leukemia by day 23. All control- and IL-11-treated allogeneic animals effectively
rejected their leukemia, but IL-11 also reduced GVHD-related mortality. Examination of the cellular
mechanisms of GVL and GVHD in this system showed that IL-11 selectively inhibited CD4-mediat-
ed GVHD, while retaining both CD4- and CD8-mediated GVL. In addition, IL-11 treatment did not
affect cytolytic effector functions of T cells after BMT either in vivo or in vitro. Studies with perforin-
deficient donor T cells demonstrated that the GVL effect was perforin dependent. These data demon-
strated that IL-11 can significantly reduce CD4-dependent GVHD without impairing cytolytic func-
tion or subsequent GVL activity of CD8+ T cells. Brief treatment with IL-11 shortly after BMT may
therefore represent a novel strategy for separating GVHD and GVL.

J. Clin. Invest.104:317-325 (1999).

\section{Introduction}

Allogeneic bone marrow transplantation (BMT) is widely performed for the treatment of hematological malignancies. It can provide antitumor activity both with intensive chemoradiotherapy and through the graft-versus-leukemia (GVL) effect associated with the transfer of donor $\mathrm{T}$ and natural killer (NK) cells, which recognize histocompatibility antigens on host leukemia cells and eradicate them (1-3). However, for leukemia, the major obstacles to a successful outcome after allogeneic BMT are still leukemia relapse and graft-versus-host disease (GVHD). GVL and GVHD are closely linked (2-4), and leukemia relapse rates after allogeneic BMT have been shown to be inversely correlated to the severity of GVHD (5). Prevention of GVHD is currently achieved by either T-cell depletion (TCD) of donor bone marrow (BM) or the use of nonspecific immunosuppressive drugs. However, because they inhibit donor $\mathrm{T}$ cells, these approaches are associated with an increased risk of leukemic relapse after $\operatorname{BMT}(5,6)$. During acute GVHD, cytokine dysregula- tion occurs as a consequence of synergistic interactions between cells of both myeloid and lymphoid lineages (7). T cells in the donor inoculum encounter alloantigen, and in the presence of IL-12, they secrete the Th1 cytokines IFN- $\gamma$ and IL-2 (8). IFN- $\gamma$ primes monocytes and macrophages to secrete cytopathic quantities of inflammatory cytokines (e.g., TNF- $\alpha$ and IL-1) after stimulation by LPS (9). This cytokine cascade contributes significantly to mediation of GVHD target-organ damage (7), whereas donor cytotoxic T lymphocytes (CTLs) and NK cells are the principal mediators of the GVL effect $(2,3)$. Therefore, inhibition of the inflammatory component of GVHD, and preservation of T-cell responses to host antigens, could represent a novel strategy for separation of GVHD and GVL after BMT.

IL-11 is a member of the IL- 6 cytokine family. Initially characterized as a hematopoietic cytokine, IL-11 has now been shown to have activity in other tissues, including those of the immune system, gastrointestinal tract, liver, and nervous system, as well as in bone 
and adipose tissue (10). IL-11 has been shown to enhance thrombopoiesis after myelosuppressive therapy $(11,12)$ and to protect against gastrointestinal injury (13). It also possesses potent anti-inflammatory properties $(14,15)$. We recently demonstrated that IL11 strongly inhibits GVHD in a well-characterized mouse model of GVHD directed against MHC and minor antigens (16). Short-term administration of IL11 not only promotes recipient survival, but provides long-term protection of GVHD target organs, especially the small intestine. The mechanisms of this effect include (a) protection of the small bowel from early GVHD toxicity; (b) suppression of systemic inflammatory cytokines such as TNF- $\alpha$; and (c) polarization of donor $\mathrm{T}$ cells toward type- 2 cytokine response. Thus, IL-11 modulates the cytokine cascade of GVHD at multiple steps. Side effects of IL-11 administration include headache, edema, tachycardia, anorexia, and dyspnea, but these are generally mild (12), making IL-11 an attractive potential adjuvant to GVHD prophylaxis.

Our initial studies demonstrated that IL-11 treatment preserves CTL function after BMT (16); we therefore hypothesized that IL-11 could maintain the GVL effect conferred by allogeneic T cells. We have now examined the effects of IL-11 on the GVL effect using 2 different experimental BMT models. Our results indicate that IL-11 treatment retains the GVL activity of allogeneic T cells and promotes leukemia-free survival after BMT. Further investigations confirm that IL11 selectively inhibits perforin-independent CD4-mediated GVHD, while retaining a perforin-dependent GVL effect mediated by both $\mathrm{CD}^{+}$and $\mathrm{CD}^{+}$cells.

\section{Methods}

Mice. Female C57BL/6 (B6, H-2 $\left.{ }^{\mathrm{b}}, \mathrm{CD} 45.2^{+}\right)$, B6D2F1 $\left(\mathrm{H}-2^{\mathrm{b} / \mathrm{d}}, \mathrm{CD} 45.2^{+}\right)(17), \mathrm{C} 3 \mathrm{FeB} 6 \mathrm{~F} 1\left(\mathrm{H}-2^{\mathrm{b} / \mathrm{k}}, \mathrm{CD} 45.2^{+}\right)$, and perforin-knockout $\mathrm{C} 57 \mathrm{BL} / 6\left(\mathrm{H}-2^{\mathrm{b}}, p f \mathrm{p}^{-/}\right)$mice were purchased from The Jackson Laboratory (Bar Harbor, Maine, USA). Female Ly-5 congenic B6.Ly-5a $\left(\mathrm{H}-2^{\mathrm{b}}\right.$, CD 45. $1^{+}$) mice were obtained from Frederick Cancer Research Facility (Frederick, Maryland, USA). The age of mice used as BMT recipients ranged between 14 and 18 weeks. Mice were housed in sterilized microisolator cages. They received normal chow and autoclaved hyperchlorinated drinking water for the first 3 weeks after BMT, and filtered water thereafter.

$B M T$. Mice were transplanted according to a standard protocol described previously (16). Briefly, on day 0 , mice received 15 Gy total body irradiation (TBI; ${ }^{137}$ Cs source), split into 2 doses that were separated by 3 hours to minimize gastrointestinal toxicity. A lower dose (11 Gy) of TBI was also used in some GVL experiments, in order to diminish GVHD mortality and to evaluate larger numbers of surviving animals in GVL experiments. After TBI, $5 \times 10^{6} \mathrm{BM}$ and $1 \times 10^{6}$ to $2 \times$ $10^{6}$ nylon wool-purified splenic donor $\mathrm{T}$ cells were resuspended in $0.25 \mathrm{~mL}$ of Leibovitz's L-15 media (GIBCO BRL, Gaithersburg, Maryland, USA) and were injected intravenously into recipients. In some experiments, allogeneic BM was depleted of T cells by incubating cells with anti-Thy- $1.2 \mathrm{mAb}$ 's at $4^{\circ} \mathrm{C}$ for 30 minutes, followed by incubation with low-toxicity rabbit complement for 40 minutes at $37^{\circ} \mathrm{C}$. Depletion of $\mathrm{CD}^{+}$and $\mathrm{CD}^{+} \mathrm{T}$ cells was performed using the MiniMACS system (Miltenyi Biotec, Bergisch Glad- a

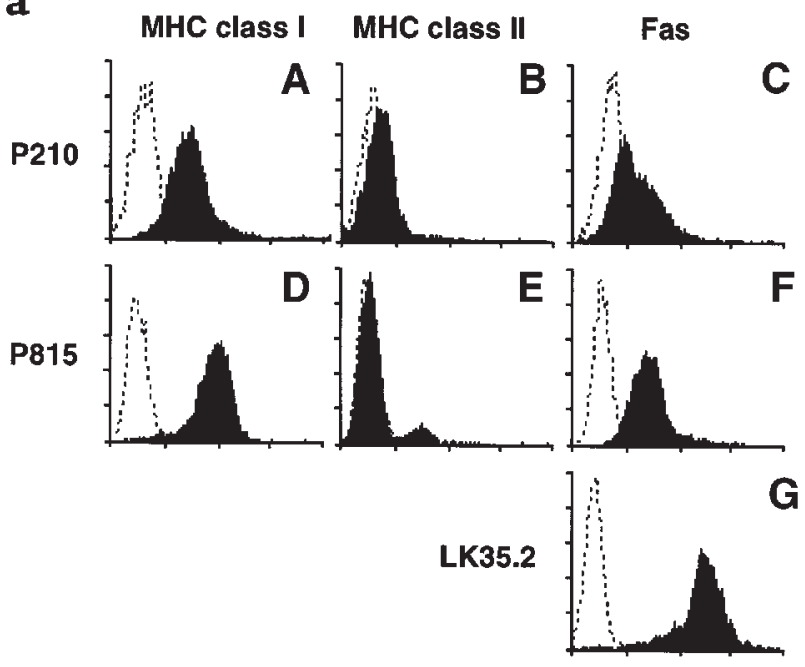

b
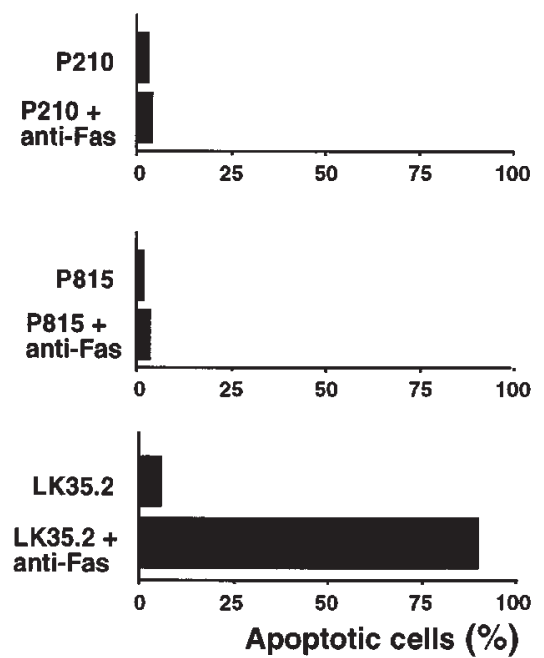

Figure 1

Characteristics of leukemic cell lines. (a) P210 and P815 cells were stained with $\mathrm{H}-2 \mathrm{~K}^{\mathrm{k}}$ and $\mathrm{H}-2 \mathrm{D}^{\mathrm{d}}$, respectively, to determine $\mathrm{MHC}$ I expression (A, D), and with I-A $\mathrm{A}^{\mathrm{k}}$ and I-A $(\mathrm{B}, \mathrm{E})$, respectively, to determine MHC II expression. Expression of membrane-bound Fas on cell surfaces was also determined (, F, G). Each graph shows staining with the indicated antibody (filled histograms) compared with the isotype control (dotted histograms). (b) Apoptosis induced by cross-linking with anti-Fas antibodies. Cells were incubated in 96-well plates coated with antiFas antibodies at $37^{\circ} \mathrm{C}$ in $5 \%$ atmospheric $\mathrm{CO}_{2}$ for 20 hours. Apoptotic cells were analyzed by flow cytometry after staining with hypotonic propidium iodide solution, and are presented as apoptotic percentage of total cells. 


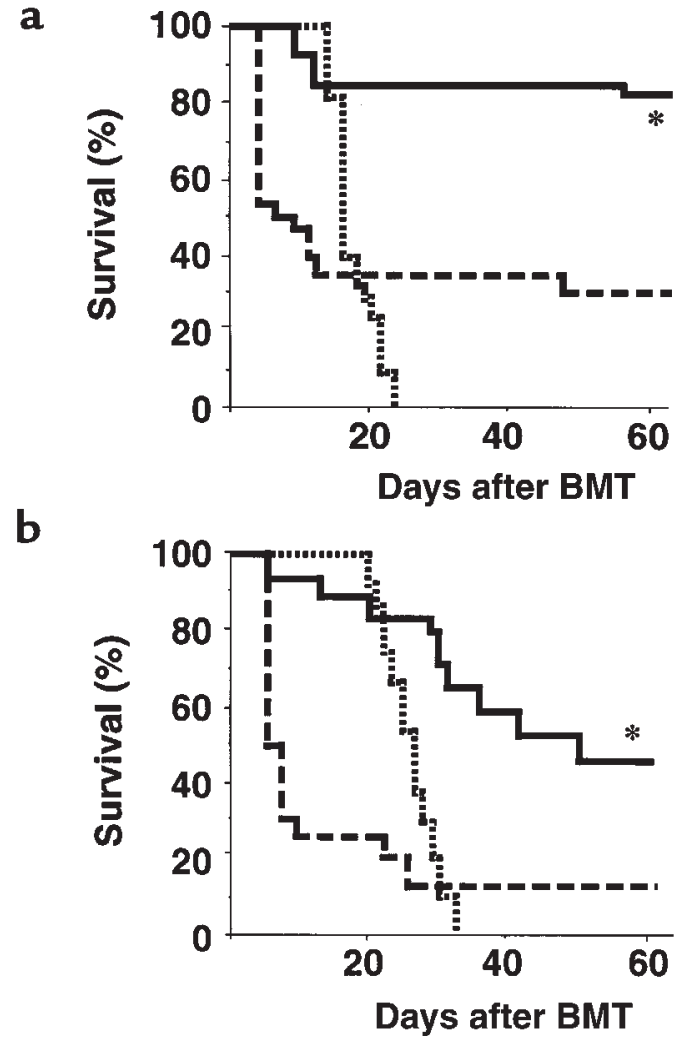

Figure 2

IL-11 promotes overall survival after BMT by reducing the mortality of GVHD while retaining GVL activity. (a) Survival in control-treated (thick dotted line; $n=25$ ) and IL-11-treated (solid line; $n=22$ ) animals after allogeneic BMT and allogeneic TCD BMT (thin dotted line; $n=16$ ). B6D2F1 mice were transplanted with $5 \times 10^{6} \mathrm{BM}$ and $1 \times 10^{6}$ splenic $\mathrm{T}$ cells from allogeneic B6 donors after 15 Gy TBI. P815 cells (2,000 per mouse) were also given intravenously on day $0 .{ }^{*} P<0.001$ vs. controltreated allogeneic animals. (b) Survival in control-treated (thick dotted line; $n=16$ ) and IL-11-treated (solid line; $n=16$ ) animals after allogeneic BMT and allogeneic TCD BMT (thin dotted line; $n=12$ ). C3FeB6F1 mice were transplanted with $5 \times 10^{6} \mathrm{BM}$ and $2 \times 10^{6}$ splenic $\mathrm{T}$ cells from B 6 donors after 15 Gy TBI. Five hundred P210 cells were given intravenously on day $0 .{ }^{*} P<0.01$ vs. control-treated allogeneic animals. In both experiments, all recipients of allogeneic BM and T cells died from GVHD; all recipients of TCD BM died from leukemia.

bach, Germany) after nylon-wool purification of spleen $T$ cells. In each experiment, cell depletion was analyzed by flow cytometry (see below) to verify that less than $0.5 \%$ of the cells of the depleted phenotype remained. Survival was monitored daily; recipient body weight and GVHD clinical score were measured weekly as described previously (18). Donor-cell engraftment was determined by examining the percentage of $\mathrm{CD} 45.1^{+}$cells in peripheral blood at day 60 after transplantation.

IL-11 treatment. Recombinant human IL-11 (kindly supplied by Genetics Institute Inc., Cambridge, Massachusetts, USA) was diluted in $0.1 \%$ BSA in PBS before injection. The protein had a specific activity of $1.6 \times 10^{6}$ to $2.1 \times 10^{6} \mathrm{U} / \mathrm{mg}$, as determined by T10 proliferation assay (19). Mice were injected subcutaneously with IL-
$11(250 \mu \mathrm{g} / \mathrm{kg}$ per dose) twice daily, from 2 days before BMT to 7 days after BMT. Recombinant human IL-11 is approximately 10 times less active in mice than in humans (J.C. Keith, Jr., personal communication). A dose of $500 \mu \mathrm{g} / \mathrm{kg}$ per day in mice is therefore equivalent to $50 \mu \mathrm{g} / \mathrm{kg}$ per day in humans, the standard dose administered clinically (12). Mice from the control groups received injection of diluent only.

FACS analysis. FITC-conjugated $\mathrm{mAb}$ 's to mouse CD45.1, CD45.2, CD4, H-2 $\mathrm{K}^{\mathrm{k}}$, and $\mathrm{H}-2 \mathrm{~K}^{\mathrm{b}}$ were purchased from PharMingen (San Diego, California, USA), as were phycoerythrin-conjugated (PE-conjugated) CD8, NK1.1, and CD95, and biotinylated I- $\mathrm{A}^{\mathrm{b}}, \mathrm{I}-\mathrm{A}^{\mathrm{d}}$, and I-A $A^{k} A b$ 's. Biotinylated mAb's were used with FITCor PE-streptavidin (PharMingen). FITC-conjugated anti-mouse $\mathrm{H}-2 \mathrm{D}^{\mathrm{d}} \mathrm{mAb}$ was purchased from Cedarlane Laboratories Ltd. (Hornby, Ontario, Canada). Cells were incubated first with $2.4 \mathrm{G} 2$ (rat anti-mouse FcrR $\mathrm{mAb}$ ) for 15 minutes at $4^{\circ} \mathrm{C}$ in order to block nonspecific Fc $\gamma \mathrm{R}$ binding of labeled antibodies, and then with the relevant $\mathrm{mAb}$ for 30 minutes at $4^{\circ} \mathrm{C}$. Cells were washed twice with $0.2 \%$ BSA in PBS, and fixed with $1 \%$ paraformaldehyde in PBS. Finally, 2-color flow cytometry was performed on a FACScan cytometer (Becton Dickinson Immunocytometry Systems, San Jose, California, USA). Irrelevant IgG2a or IgG2b mAb was used as a negative control. Ten thousand live events were acquired for analysis.

Leukemia induction. P815 (H-2 $\left.{ }^{\mathrm{d}}, \mathrm{CD} 45.2^{+}\right)$is a mastocytoma derived from a DBA/2 mouse. 32Dp210 (P210) is an $\mathrm{H}-2^{\mathrm{k}}, \mathrm{CD} 45.2^{+}$myeloid leukemia derived from $32 \mathrm{D}$ cells of $\mathrm{C} 3 \mathrm{H} / \mathrm{Hej}$ mouse origin, transformed by $\mathrm{p} 210$ bcr/abl oncogene (20). P815 and P210 cells were injected intravenously into B6D2F1 recipients and $\mathrm{C} 3 \mathrm{FeB} 6 \mathrm{~F} 1$ recipients, respectively, on day 0 of BMT. Survival was monitored daily, and the cause of each death after BMT was determined (by postmortem examination) to be either GVHD or leukemia. The most striking leukemiaspecific abnormality induced by P210 was marked hepatosplenomegaly (spleen more than $400 \mathrm{mg}$ and liver more than $1,700 \mathrm{mg}$ ). No hepatosplenomegaly was found in animals that had not received P210. In contrast to the diffuse infiltration of P210 cells, P815 cells tend to form macroscopic nodules, preferentially in liver and spleen. In some animals, lower-limb paralysis developed; histopathological analysis revealed infiltration of P815 cells around the spinal cord. The specificity of lower-limb paralysis for leukemic death was quite high, as paralysis was never seen in animals not given P815 cells. A P815-induced leukemic death was therefore defined by the occurrence of either macroscopic tumor nodules in liver and/or spleen, or hindleg paralysis. GVHD death was defined by the absence of leukemia and the presence of clinical signs of GVHD, assessed by a clinical scoring system described previously (18). In some experiments, sentinel carcasses were placed in 10\% formalin in PBS, and pathological examination was performed after staining with hematoxylin and eosin.

Animals surviving beyond day 60 of BMT were sacri- 


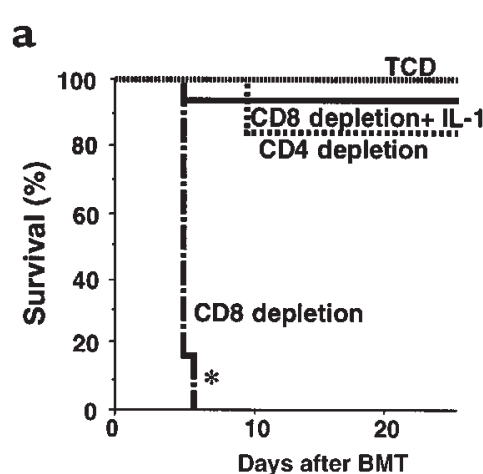

c

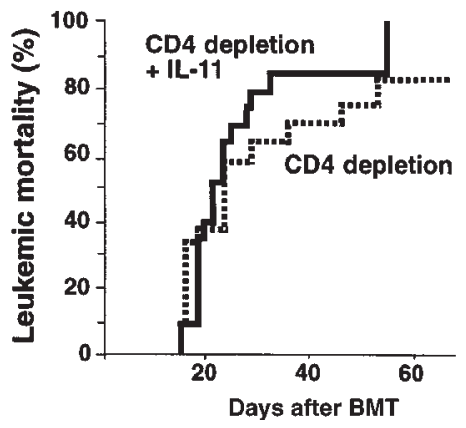

b

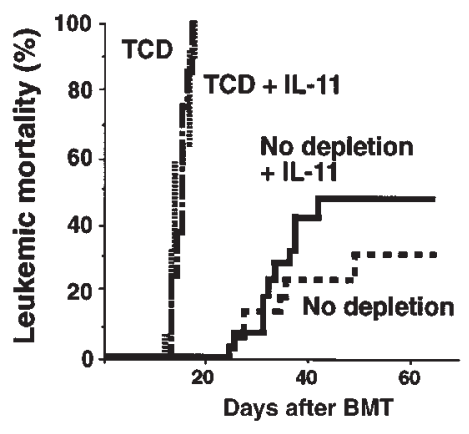

d

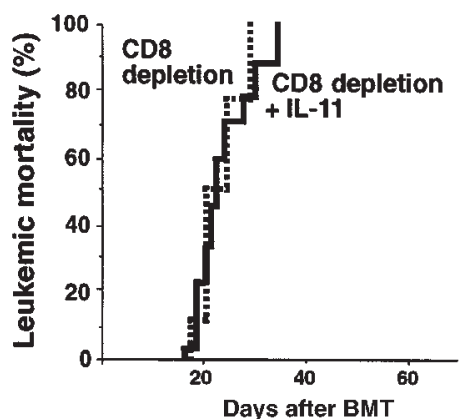

Figure 3

IL-11 inhibits CD4-mediated GVHD while preserving both CD4- and CD8-mediated GVL effects. (a) Survival in control-treated recipients of TCD BM alone (thin dotted line; $n=5$ ), CD4-depleted T cells (thick dotted line; $n$ $=8$ ), and CD8-depleted T cells (broken dotted line; $n=$ 8); and in IL-11-treated recipients of CD8-depleted T cells (solid line; $n=8$ ) after BMT. Lethally irradiated (15 Gy) B6D2F1 mice were transplanted with $5 \times 10^{6} \mathrm{TCD} B M$, alone or with $1 \times 10^{6} \mathrm{CD} 4$ - or CD8-depleted T cells from B6 donors. ${ }^{*} P<0.0001$ vs. control-treated recipients of CD4-depleted T cells or IL-11-treated animals receiving CD8-depleted T cells. (b, c, and d) Leukemic mortality. B6D2F1 mice were transplanted as described above after 11 Gy TBI. Five thousand P815 cells were injected intravenously on day 0 . GVHD deaths were not counted. (b) Leukemic mortality in animals treated with control (thick dotted line; $n=20$ ) and IL-11 (solid line; $n=20$ ) after allogeneic BMT, and in animals treated with control (thin dotted line; $n=12$ ) and IL-11 (broken dotted line; $n=8$ ) after allogeneic TCD BMT. (c) Leukemic mortality in animals treated with control (thick dotted line; $n=20$ ) and IL-11 (solid line; $n=24$ ) after CD4-depleted BMT. (d) Leukemic mortality in animals treated with control (thick dotted line; $n=8$ ) and IL-11 (solid line; $n=8$ ) after CD8depleted BMT. ficed, and the liver and spleen were harvested for histological evaluation. Peripheral blood was obtained for FACS analysis to determine leukemia-free survival, which was defined by the absence of clinical manifestations of leukemia and by the absence of leukemia cells in the peripheral blood (less than $0.5 \% \mathrm{H}-2 \mathrm{D}^{\mathrm{d}+} / \mathrm{H}-2 \mathrm{~K}^{\mathrm{b}-}$ or CD45.2 $2^{+}$CD45.1- cells in P815 experiments, and less than $0.5 \% \mathrm{H}-2 \mathrm{~K}^{\mathrm{k}+} / \mathrm{H}-2 \mathrm{~K}^{\mathrm{b}-}$ or CD $45.2^{+} / \mathrm{CD} 45.1^{-}$cells in P210 experiments). In experiments mixing B6 Ly-5a splenocytes with either P815 or P210 cells, the minimal detectable level of leukemic contamination was $0.5 \%$.

Apoptosis assay. We coated 96-well plates overnight at $4^{\circ} \mathrm{C}$ with anti-Fas antibodies $(\mathrm{Jo} 2 ; 1 \mathrm{mg} / \mathrm{mL})$, and cells $\left(10^{6} / \mathrm{mL}\right)$ were incubated for 20 hours at $37^{\circ} \mathrm{C}$ in an atmosphere of $5 \% \mathrm{CO}_{2}$. Apoptotic cells were analyzed by flow cytometry after staining with hypotonic propidium iodide solution as described. Briefly, $2 \times 10^{5}$ cells were incubated for 10 minutes at $4^{\circ} \mathrm{C}$ with $200 \mu \mathrm{L}$ of hypotonic buffer containing $0.1 \%$ sodium citrate, 0.1\% Triton X-100 (Sigma Chemical Co., St. Louis, Missouri, USA), and $50 \mathrm{mg} / \mathrm{mL}$ propidium iodide. The cell suspension was then analyzed by flow cytometry, and the subdiploid peak was measured to determine the percentage of apoptotic cells.

${ }^{51} \mathrm{Cr}$ release assays. Splenocytes were removed from $\mathrm{B} 6 \mathrm{D} 2 \mathrm{~F} 1$ recipients 14 days after BMT, and 3 spleens were combined from each group. These cells were then layered over Ficoll-Paque (Amersham Pharmacia Biotech, Piscataway, New Jersey, USA) and centrifuged at $800 \mathrm{~g}$ for 20 minutes. Cells were then collected from the interface and washed twice before suspension in supplemented 10\% heat-inactivated FCS in RPMI. The percentage of $\mathrm{CD}^{+}$cells in this fraction was determined by FACS analysis, and counts were normalized for $\mathrm{CD}^{+} \mathrm{T}$-cell numbers. Variation in the percentage of $\mathrm{CD}^{+}$cells in the spleens of animals treated with IL-11 and control was less than $10 \%$, without appreciable differences in $\mathrm{CD}^{+} / \mathrm{CD}^{+}$ratios. P815 $\left(\mathrm{H}-2^{\mathrm{d}}\right)$, EL4 $\left(\mathrm{H}-2^{\mathrm{b}}\right)$, Fas-sensitive target LK35.2 $\left(\mathrm{H}-2^{\mathrm{d} / \mathrm{k}}\right)(21)$, and NK-sensitive target cell YAC-1 $\left(\mathrm{H}-2^{\mathrm{a}}\right)$ were used as targets. Tumor targets $\left(2 \times 10^{6}\right.$ cells $)$ were labeled with $100 \mu \mathrm{Ci}$ of ${ }^{51} \mathrm{Cr}$ for 2 hours. After being washed 3 times, labeled targets were plated with $1 \times 10^{4}$ cells per well in U-bottom 96-well plates (Corning-Costar Corp., Cambridge, Massachusetts, USA). Splenocytes (prepared as described) were added to quadruplicate wells at varying effector/target ratios, and incubated for 4 or 7 hours. ${ }^{51} \mathrm{Cr}$ activity in supernatants was determined in an auto-gamma counter (Packard Instrument Company, Meriden, Connecticut, USA). Maximal and background release were determined by the addition of $2 \%$ Triton X-100 or media alone to targets, respectively. The percentage of specific lysis was calculated as follows: $100 \times($ sample count - background count $) /(\max -$ imal count - background count).

Statistical analysis. Survival curves were plotted using Kaplan-Meier estimates. The Mantel-Cox log rank test was used to analyze survival data. Statistical significance was set at $P<0.05$.

\section{Results}

Characteristics of P815 and P210 leukemia cell lines. After TCD BMT, P815 and P210 cells proliferate in liver, spleen, BM, and peripheral blood. FACS analysis demonstrated that both cell lines express significant amounts of MHC class I (but few class II) molecules on their surfaces (Figure 1a). Both leukemias are resistant to lysis mediated by cross-linking with anti-Fas antibodies in 
vitro (Figure 1b), despite their expression of membranebound Fas (Figure 1a). By contrast, LK35.2 cells are exquisitely sensitive to lysis induced by the ligation of Fas with anti-Fas antibodies (Figure 1b). IL-11 did not enhance the growth of either P815 or P210 cells in vitro (data not shown).

IL-11 promotes leukemia-free survival after BMT by reducing $G V H D$ and retaining the GVL effect. In preliminary experiments, we determined that 2,000 P815 and 500 P210 leukemic cells were $100 \%$ lethal when given to B6D2F1 and $\mathrm{C} 3 \mathrm{FeB} 6 \mathrm{~F} 1$ recipients of TCD BMT, respectively (data not shown). These doses were therefore used in allogeneic BMT to mimic minimal residual disease and to study the effect of IL-11 administration on GVL effects. B6D2F1 recipients received BMT and either IL11 or control treatment as described above. Two thousand P815 cells were added to the BM inoculum on day 0 . As shown in Figure 2a, all recipients of TCD BM died from leukemia by day 23 after BMT, without evidence of GVHD. In control-treated allogeneic BMT recipients, GVHD was severe, with mortality beginning on day 5; only $32 \%$ of animals survived at day 60 . By contrast, $82 \%$ of IL-11-treated allogeneic animals survived this period $(P<0.001)$. In each case, allogeneic recipients effectively rejected their leukemia, and mortality was due solely to GVHD (all surviving animals were sacrificed at day 60, and no evidence of leukemia was found postmortem). In addition, FACS analysis of peripheral blood showed complete donor-cell engraftment $(99.5 \pm 0.2 \%$ in IL11 -treated animals; $98.6 \pm 0.8 \%$ in control-treated animals) without any detectable P815 cells $\left(\mathrm{H}-2^{\mathrm{d}^{+}} / \mathrm{H}-2^{\mathrm{b}-}\right)$. Surviving allogeneic BMT control animals developed significantly more severe clinical GVHD than did IL11 -treated animals (clinical score at day 60 was $4.4 \pm 0.5$ vs. $2.6 \pm 0.4$, respectively; $P<0.05$ ). These results indicate that IL-11 promotes leukemia-free survival after BMT by inhibiting GVHD and maintaining GVL activity.

Similar results were obtained in a different experimental BMT model using $\mathrm{C} 3 \mathrm{FeB} 6 \mathrm{~F} 1$ recipient mice and B6 donors. In this model, the transplanted cells were P210 $\left(\mathrm{H}-2^{\mathrm{k}}\right)$ leukemic cells bearing MHC antigens of the recipients $\left(\mathrm{H}-2^{\mathrm{b} / \mathrm{k}}\right)$ but not the donors $\left(\mathrm{H}-2^{\mathrm{b}}\right)$. All the recipients of TCD BM died of leukemia by day 32 after BMT, with a median survival time of 25 days (Figure 2b). Severe GVHD developed in allogeneic animals. However, survival at day 60 after BMT in the IL-11 group was significantly greater than in the control group ( $44 \%$ vs. $12 \%$, respectively; $P<0.01$ ). No deaths from leukemia were seen in either group, again confirming that IL-11 promotes leukemia-free survival after allogeneic BMT.

IL-11 inhibits CD4-mediated GVHD after BMT. We next examined the role of T-cell subsets in mediating GVHD in our system. To evaluate the requirement for $\mathrm{CD} 4^{+}$and $\mathrm{CD}^{+} \mathrm{T}$ cells in producing GVHD, we selectively depleted $\mathrm{CD}^{+}$or $\mathrm{CD}^{+} \mathrm{T}$ cells from $\mathrm{B} 6$ spleen $\mathrm{T}$ cells, using the MiniMACS system described in Methods. FACS analysis showed that depletion of each subset was always greater than 99.5\%. Lethally irradiated (15 Gy) B6D2F1 recipients were then transplanted with $1 \times 10^{6} \mathrm{CD} 4$-depleted or CD8-depleted T cells, with $5 \times 10^{6} \mathrm{TCD}$ BM. In each set of experiments a subgroup of mice also received IL11 (Figure 3a). Depletion of $\mathrm{CD}^{+} \mathrm{T}$ cells from the donor-cell inoculum effectively eliminated GVHD mortality, whereas depletion of $\mathrm{CD}^{+} \mathrm{T}$ cells did not $(P<$ 0.0001). Administration of IL-11 prevented GVHD mortality mediated by $\mathrm{CD}^{+}{ }^{+} \mathrm{T}$ cells compared with no IL-11 treatment $(P<0.0001)$. These results demonstrate that acute GVHD in this model is dependent on allogeneic $\mathrm{CD}^{+} \mathrm{T}$ cells, consistent with earlier experiments (22).
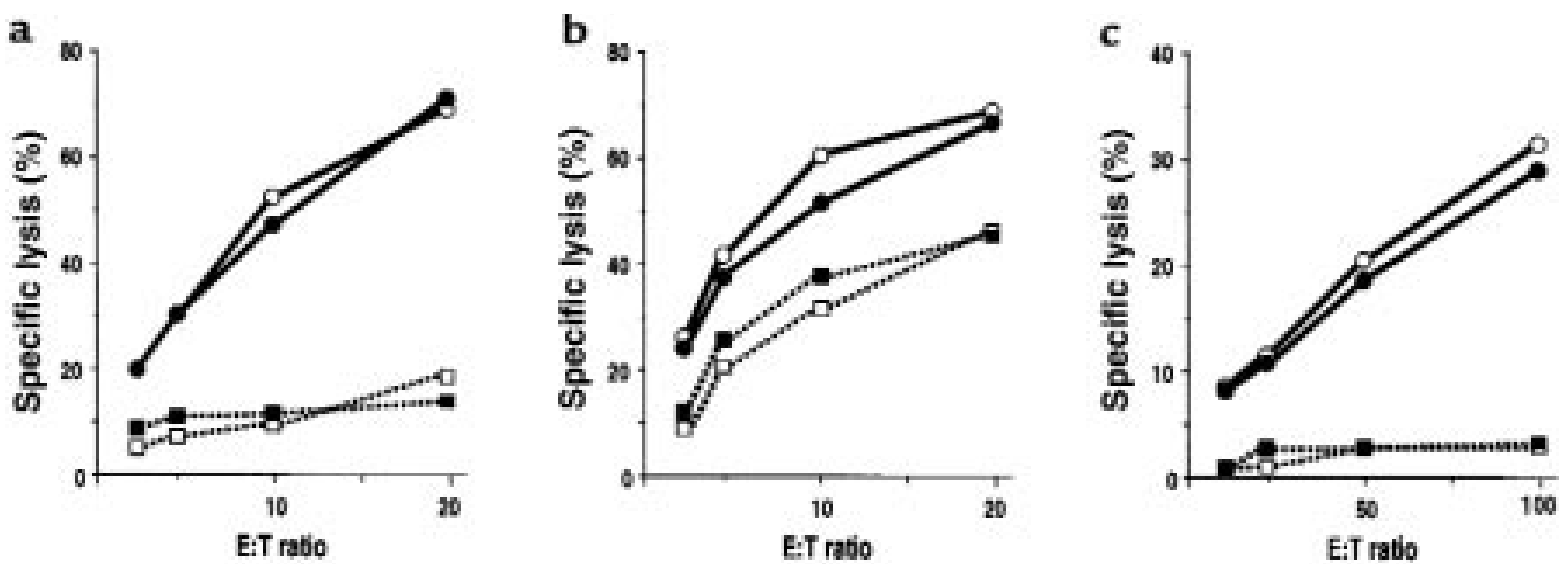

Figure 4

IL-11 treatment preserves CTL function after BMT. Splenocytes harvested from allogeneic animals on day 14 of BMT were pooled $(n=3)$ and used immediately in a ${ }^{51} \mathrm{Cr}$ release assay. (a) CTL activity against P815 in control-treated (open circles) and IL-11-treated (filled circles) recipients of wild-type donor T cells, and in control-treated (open squares) and IL-11-treated (filled squares) recipients of $p f p^{-/-}$donor T cells after 7 hours in culture. (b) CTL activity against LK35.2 in control-treated (open circles) and IL-11-treated (filled circles) recipients of wildtype donor T cells, and in control-treated (open squares) and IL-11-treated (filled squares) recipients of $p f p^{-1-}$ donor T cells after 7 hours in culture. (c) CTL against YAC-1 in control-treated (open circles) and IL-11-treated (filled circles) recipients of wild-type donor T cells, and in control-treated (open squares) and IL-11-treated (filled squares) recipients of $\mathrm{pfp}^{-/-}$donor T cells after 4 hours in culture. 
GVL depends on both $C D 4^{+}$and $C D 8^{+} T$ cells and is not affected by IL-11 treatment. We next investigated the ability of $\mathrm{CD}^{+}$and $\mathrm{CD}^{+} \mathrm{T}$ cells to mediate the GVL effect in this model. In these experiments, conditioning of 11 Gy was used, which reduced the intensity of GVHD and allowed the evaluation of larger numbers of surviving animals. The P815 dose was concomitantly increased to 5,000 cells per animal to increase the stringency of the leukemia challenge. B6D2F1 recipients received $5 \times$ $10^{6} \mathrm{TCD} \mathrm{BM}$, alone or with $1 \times 10^{6}$ unselected T cells, CD4-depleted T cells, or CD8-depleted T cells from B6 donors (after 11 Gy TBI). As expected, mortality from acute GVHD was low under these conditions (even unselected donor T cells were successfully transplanted); GVHD deaths in this group were observed in 4 of 20 control animals and 3 of 20 IL-11-treated recipients. All recipients of TCD BM alone died of leukemia within 3 weeks of BMT (Figure 3b). Of note, IL-11 treatment did not affect in vivo tumor growth in the absence of T cells; the rate of leukemia death in recipients of TCD BM was the same in both the IL-11 and control treatment groups. When GVL was induced by unselected T cells, leukemic mortality in control- and IL-11-treated recipients was similar at day 60 of BMT ( $32 \%$ vs. $50 \%, P=0.26$; Figure $3 \mathrm{~b}$ ). Depletion of either CD4 or CD8 delayed, but did not decrease, leukemic death; the median survival time of recipients of TCD BM alone, CD4-depleted T cells, and CD8-depleted T cells was 14, 23, and 21 days, respectively $(P<0.001$; Figure $3, b-d)$. These results show that both $\mathrm{CD}^{+}$and $\mathrm{CD}^{+} \mathrm{T}$ cells are required for optimal GVL activity in this system. The rate of leukemic mortality in recipients of either CD4- or CD8-depleted T cells was similar in groups with and without IL-11 treatment, demonstrating that IL-11 administration did not diminish the magnitude of the GVL effect of either T-cell subset.

Interestingly, leukemic death was associated with hepatosplenomegaly in recipients of CD8-depleted, but not CD4-depleted, T cells $(P<0.01$; Table 1$)$. Therefore, the recipients of $\mathrm{CD}^{+}$cells died with higher leukemic burdens than did recipients of $\mathrm{CD}^{+}$cells, suggesting

Table 1

IL-11 effects on leukemic burden

\begin{tabular}{ccccc}
\hline Donor & $\begin{array}{c}\text { T-cell } \\
\text { depletion }\end{array}$ & $\begin{array}{c}\text { IL-11 } \\
\text { treatment }\end{array}$ & \multicolumn{2}{c}{ Weight $(\mathrm{mg})$} \\
B6 & - & $\pm^{\mathrm{A}}$ & $78 \pm 39^{\mathrm{B}}$ & $1,255 \pm 458^{\mathrm{B}}$ \\
& Thy-1.2 & $\pm^{\mathrm{A}}$ & $341 \pm 139$ & $1,986 \pm 506$ \\
& $\mathrm{CD} 4$ & - & $68 \pm 41^{\mathrm{B}}$ & $1,023 \pm 140^{\mathrm{B}}$ \\
& $\mathrm{CD} 4$ & + & $71 \pm 18^{\mathrm{B}}$ & $1,044 \pm 91^{\mathrm{B}}$ \\
& $\mathrm{CD} 8$ & - & $280 \pm 49$ & $1,602 \pm 140$ \\
& $\mathrm{CD} 8$ & + & $290 \pm 178$ & $1,834 \pm 312$ \\
$\mathrm{pfp} \mathrm{p}^{-/-}$ & - & - & $254 \pm 62$ & $3,148 \pm 699$ \\
& - & + & $328 \pm 117$ & $3,093 \pm 680$
\end{tabular}

B6D2F1 mice were transplanted with $5 \times 10^{6} \mathrm{TCD} B M$, alone or with $1 \times 10^{6}$ whole T cells, CD4-depleted T cells, or CD8-depleted T cells from B6 or pfp $\mathrm{pt}^{-1}$ donors after 11 Gy TBI. Five thousand P815 cells were injected intravenously on day 0 . Spleen and liver were weighed postmortem. ${ }^{A}$ Combined data with and without IL-11. ${ }^{\mathrm{B} P}<0.01$ compared with TCD (Thy-1.2) animals. that $\mathrm{CD}^{+} \mathrm{T}$ cells are more potent effectors of GVL than are $\mathrm{CD} 4^{+}$cells, but they require $\mathrm{CD} 4$ help to exert their maximal GVL effect. Hepatosplenomegaly was not observed in IL-11-treated recipients of CD4depleted $T$ cells, again demonstrating that the ability of $\mathrm{CD}^{+} \mathrm{T}$ cells to suppress leukemia in the absence of $\mathrm{CD}^{+} \mathrm{T}$ cells was not diminished by IL-11 treatment.

IL-11 preserves CTL function mediated by both perforin and Fas after BMT. To investigate the molecular mechanisms of GVL in this model, we first examined the cytolytic activity of donor splenocytes with respect to host targets. Splenocytes were harvested from B6D2F1 recipients on day 14 after BMT. Strong CTL activity was demonstrated in splenocytes from recipients of wildtype B6 $\left(\mathrm{H}-2^{\mathrm{b}}\right)$ donor cells in culture with host-type P815 (H-2 $\left.{ }^{\mathrm{d}}\right)$ targets (Figure $\left.4 \mathrm{a}\right)$. No lysis was observed in this assay when perforin-deficient $\left(p f p^{-/-}\right)$mice $\left(\mathrm{H}-2^{\mathrm{b}}\right)$ were used as donors, or when donor type EL4 $\left(\mathrm{H}-2^{\mathrm{b}}\right)$ cells were used as targets (data not shown), confirming perforin-dependent, allospecific killing.

The Fas/FasL system is a second important effector pathway of CTL function, so we examined the effect of IL-11 on Fas-mediated cytotoxicity after allogeneic BMT using LK35.2 targets, which express high levels of Fas on their surfaces (Figure 1). Consistent with Fasrestricted killing, $\mathrm{pfp}^{-/-}$effectors significantly lysed LK35.2 but not Fas-resistant P815 or YAC-1 cells (Figure 4b). IL-11 treatment did not reduce either the perforin- or Fas-dependent cytolytic activity of donor $\mathrm{T}$ cells against host targets (Figure 4, a and b). IL-11 also did not reduce cytolytic activity against NK-sensitive YAC-1 targets; such activity was almost completely perforin dependent (Figure 4c).

IL-11 inbibits GVHD in a perforin-independent fashion but retains the perforin-dependent GVL effect. We next examined effector mechanisms of T cell-mediated GVHD and GVL using perforin-deficient donor mice. B6D2F1 recipients were transplanted with $5 \times 10^{6} \mathrm{BM}$ and $1 \times$ $10^{6} \mathrm{~T}$ cells from wild-type B6 or $\mathrm{pfp}^{-/-}$donors after $15 \mathrm{~Gy}$ TBI. Survival of recipients of T cells from wild-type B6 and $\mathrm{pp}^{-1-}$ donors was $50 \%$ and $63 \%$, respectively ( $P=$ 0.86; Figure 5a). Administration of IL-11 inhibited the GVHD mortality induced by $\mathrm{pfp}^{-1-} \mathrm{T}$ cells $(P<0.001$; Figure $5 \mathrm{a}$ ). We next investigated the role of perforin in the GVL effect in this system. All TCD BMT recipients from wild-type B6 donors died from leukemia by day 17 after $\mathrm{BMT}$, whereas no BMT recipients of $\mathrm{T}$ cells from wildtype B6 donors died, regardless of whether IL-11 was administered (Figure 5b). By contrast, GVL was markedly reduced when $p f p^{-/-}$mice were used as donors; all recipients of these donor cells died from leukemia $(P<$ 0.001), with or without IL-11 treatment. Leukemic mortality in recipients of $\mathrm{pfp}^{-/-}$cells was delayed approximately 5 days compared with that in recipients of TCD $\mathrm{BM}$, suggesting a weak GVL effect that was independent of perforin. Taken together, these results demonstrate that perforin-mediated cytotoxicity does not play a significant role in GVHD mortality in this model, but it is critical for the eradication of P815 cells, which is not 
impaired by IL-11 treatment. Of note, leukemic death in the recipients of $\mathrm{pfp}^{-1-} \mathrm{T}$ cells was associated with marked hepatosplenomegaly (Table 1) and was similar to that seen in recipients of CD8-depleted T cells.

\section{Discussion}

In recent years, much attention has been focused on the role of cytokine cascades in GVHD pathophysiology $(7,23)$. We recently reported that IL- 11 achieves GVHD suppression at 3 steps within the cytokine cascade of acute GVHD (16). IL-11 minimizes GVHD damage to the small bowel during radiation conditioning, which prevents translocation of LPS from the intestinal lumen into the systemic circulation. IL-11 also prevents TBI-induced increases in secretion of TNF- $\alpha$ and IL- 12 by host macrophages. As a consequence, during donor T-cell activation, IL-11 induces polarization of donor $\mathrm{T}$ cells toward type- 2 cytokine response. Thus, the protective effects of IL-11 from GVHD are primarily mediated by the reduction of the inflammatory toxicities of GVHD. Our initial studies also demonstrated that CTL activity was preserved after IL-11 treatment (16). We hypothesized that the ability of IL-11 to suppress the inflammatory toxicities of GVHD while preserving CTL function could permit the separation of the GVL effect from GVHD. This study supports that hypothesis in 2 different experimental models of BMT for leukemia. Both models show that IL-11 promotes leukemia-free survival after allogeneic BMT by reducing GVHD while maintaining GVL activity. In addition, we show that the molecular pathways of cytolysis in CTLs that are mediated by perforin and FasL are not affected by IL-11 treatment in vivo, and that the GVL effect depends primarily on the perforin pathway.

Severe, acute GVHD in this donor/recipient strain combination is primarily dependent on donor $\mathrm{CD}^{+} \mathrm{T}$ cells; depletion of $\mathrm{CD}^{+} \mathrm{T}$ cells from the donor inoculum markedly inhibited GVHD mortality. This observation confirmed earlier studies in which $\mathrm{CD} 4^{+} \mathrm{T}$ cells were found to play a critical role in inducing GVHD across full MHC barriers in several different murine strain combinations $(22,24-27)$. $\mathrm{CD}^{+} \mathrm{T}$ cells contribute to GVHD through their cytolytic activity (28, 29) and cytokine production, which helps to amplify $\mathrm{CD}^{+}$CTL generation and prime macrophages to produce inflammatory cytokines (7). Of note, acute GVHD mortality in this system (B6 donor to $\mathrm{B} 6 \mathrm{D} 2 \mathrm{~F} 1$ recipient) is inhibited by a lower TBI dose, which in turn reduces macrophage secretion of TNF- $\alpha$ (30). IL-11 prevents this effect of TBI (16), consistent with the importance of inflammatory cytokine dysregulation in mediating GVHD that is initiated by $\mathrm{CD} 4^{+} \mathrm{T}$ cells.

In our model, both $\mathrm{CD} 4^{+}$and $\mathrm{CD} 8^{+} \mathrm{T}$-cell populations were required for a GVL effect. The P815 cells used in these experiments were MHC I positive but MHC II negative; we interpret the dependence on $\mathrm{CD}^{+}$and $\mathrm{CD}^{+}$ subsets to mean that $\mathrm{CD}^{+} \mathrm{T}$ cells are necessary for the expansion and activation of $\mathrm{CD} 8^{+}$effectors that direct- $\mathbf{a}$

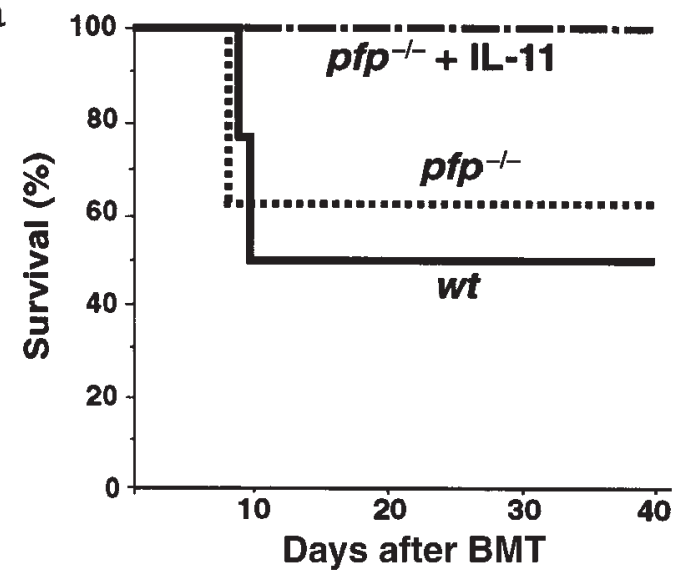

b

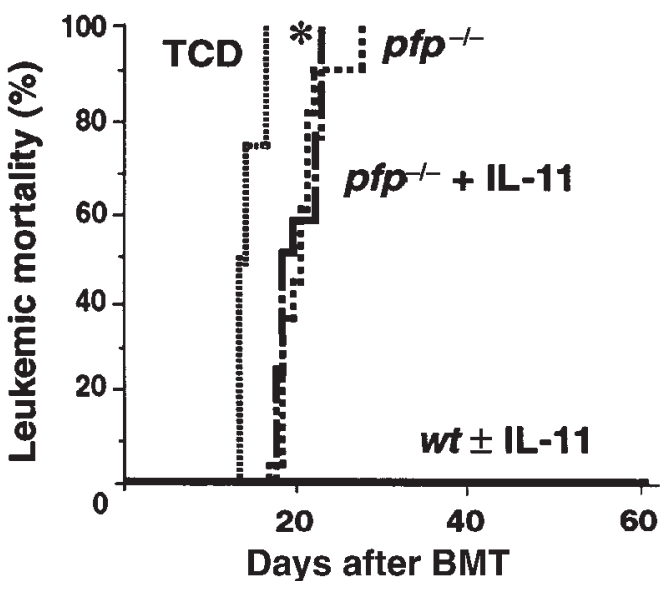

Figure 5

IL-11 inhibits GVHD in a perforin-independent fashion, but retains the perforin-dependent GVL effect. (a) Lethally irradiated (15 Gy) B6D2F1 mice were transplanted with $5 \times 10^{6} \mathrm{BM}$ and $1 \times 10^{6}$ splenic T cells from wild-type B6 (wt) or $\mathrm{fp}^{-/-}$donors. Survival in control-treated (thin dotted line; $n=8$ ) and IL-11-treated (broken dotted line; $n=$ 8) recipients of T cells from $p f^{-1-}$ donors, and in control-treated recipients ofT cells from wild-type donors (solid line; $n=6$ ) after BMT. (b) B6D2F1 mice were transplanted as described above after 11 Gy TBI. Two thousand P815 cells were injected intravenously on day 0 . Leukemic mortality after BMT in control- or IL-11-treated recipients of T cells from wild-type donors (solid line; $n=16$ ), in control-treated (thick dotted line; $n=8$ ) and IL-11-treated (broken dotted line; $n$ $=8$ ) recipients of $\mathrm{pfp}^{-1-} \mathrm{T}$ cells, and in control-treated animals receiving TCD BMT (thin dotted line; $n=4$ ). ${ }^{*} P<0.01$ vs. recipients of either TCD BM or T cells from wild-type B6 donors.

ly lyse P815 cells. Alone, $\mathrm{CD}^{+} \mathrm{T}$ cells conferred minimal GVL activity (all animals died of leukemia), but death was delayed approximately 10 days by the addition of $\mathrm{CD}^{+} \mathrm{T}$ cells to the BM (Figure 3 ). This modest CD4mediated GVL effect against MHC II-negative, Fasresistant $\mathrm{P} 815$ suggests that inflammatory cytokines (TNF- $\alpha$, IFN- $\gamma$, IL-1) secreted during GVHD, or novel members of the TNF family (TRAIL) (31-33), may retard - but not eliminate - leukemia. Interestingly, the CD4-mediated effect was not altered by IL-11 treatment, despite the marked suppression by IL-11 of CD4mediated GVHD. This dichotomy suggests that IL-11 may modulate the cytokine production of $\mathrm{CD}^{+} \mathrm{T}$ cells 
without impairing other functions, similar to the effect of IL- 11 on $\mathrm{CD}^{+} \mathrm{T}$ cells.

Other cytokines have been shown to reduce GVHD while retaining GVL. Administration of both IL-2 and IL-12 can selectively inhibit $\mathrm{CD} 4^{+} \mathrm{T}$ cells, and thereby inhibit GVHD, in a fully MHC- and minor antigen-mismatched BMT model (A/J donor to B10 recipient), while partially preserving a GVL effect that is mediated by $\mathrm{CD}^{+} \mathrm{T}$ cells $(26,27)$. IL- 2 can also preserve a GVL effect when it is dependent on both CD4 ${ }^{+}$ and $\mathrm{CD}^{+}$cells, as in our model (34).

In recent years, it has become clear that the cytolytic activity of $T$ cells is primarily mediated through at least 2 distinct pathways: perforin/granzyme and Fas/FasL. $\mathrm{CD}^{+}$CTLs, NK cells, and lymphokine-activated killer (LAK) cells primarily depend on the perforin/granzyme pathway to kill their targets, whereas $\mathrm{CD} 4^{+}$CTLs use Fas and other mechanisms, including inflammatory cytokines such as TNF- $\alpha$ and IFN- $\gamma$, and novel members of the TNF family (TRAIL) $(31,33,35-41)$. In this study, the role of cell-mediated cytotoxicity in GVHD and GVL was analyzed through the use of $\mathrm{pfp}^{-/-}$donor mice, which lack the capacity to lyse cells via perforin, although Fas/FasL-mediated cytotoxicity is unimpaired $(36,39)$. Our data show that GVHD mortality was not mediated by perforin (Figure 5a), which is consistent with the lack of a major role for perforin in other CD4mediated GVHD models $(29,42)$. Our data do not agree with those of Blazar et al. (43), who used a nonlethal dose of TBI ( 6 Gy). The lower TBI dose reduces inflammatory cytokine secretion from macrophages (30), a situation in which the induction of GVHD may require additional cytolytic pathways. The gastrointestinal tract seems particularly susceptible to the toxicity of inflammatory cytokines generated during GVHD (44); IL-11 reduces this susceptibility by maintaining epithelial cellular structure, and indirectly by suppressing the production of inflammatory cytokines (16).

Although perforin was not a critical mediator of GVHD in this model, it was an important mediator of GVL against P815. This is consistent with the expression of MHC class I (but not class II) on P815 cells (Figure 1a), because $\mathrm{CD}^{+}$CTLs primarily depend on the perforin/granzyme pathway to kill their MHC I+ targets (36, 38, 39); P815 cells are not sensitive to Fas-mediated killing in vitro, as shown in Figure 1b. These results confirm a recent report demonstrating perforin-independent GVHD and perforin-dependent GVL using this same experimental BMT-leukemia model (45). Fas resistance seems to be one mechanism by which tumors can escape from immune surveillance $(46,47)$, and tumors that express Fas on their surface are not always susceptible to Fas-dependent lysis $(48,49)$. Studies in $p f p^{-/-}$mice have demonstrated that perforin was critical for tumor elimination, and the Fas system played little part (47). IL-11 retained the perforin-mediated GVL effect against P815 and, interestingly, did not perturb Fas/FasL-mediated CTL activity (Figure 4b). The small but significant delay in leukemic mortality in recipients of $p \mathrm{fp}^{-/-} \mathrm{T}$ cells com- pared with TCD recipients $(P<0.01)$ is likely due to other cytolytic mechanisms (Figure 5 b). This remaining GVL activity mediated by nonperforin mechanisms was also unaffected by IL-11 treatment (Figure $5 \mathrm{~b}$ ).

In summary, IL-11 administration markedly inhibited CD4-dependent GVHD, but retained a GVL effect through unaltered CTL function mediated primarily by perforin. Thus, separation of GVL from GVHD by IL-11 in this model is explained by the selective inhibition of inflammatory cytokines and by preservation of $\mathrm{T}$ cell-mediated effector mechanisms of tumor lysis. Current immunosuppressive drugs such as cyclosporin A and prednisone offer significant but incomplete protection against GVHD - particularly in the setting of multiple donor-host histocompatibility antigen disparities that pertain to unrelated donor BMT - and can negatively impact the GVL effect through their suppression of T cells. Brief administration of IL-11 may represent a novel strategy for separation of GVHD and GVL, and may serve as an effective adjunct to clinical regimens of GVHD prophylaxis.

\section{Acknowledgments}

This work was supported by National Institutes of Health grants CA-39542 and HL-55162 (to J.L.M. Ferrara). M.R.M. van den Brink is the recipient of a Howard Hughes Physician Scientist Postdoctoral Fellowship.

1. Bortin, M., Rimm, A., and Saltzstein, E. 1973. Graft-versus-leukemia: Quantification of adoptive immunotherapy in murine leukemia. Science. 173:811-813.

2. Truitt, R.J., and Johnson, B.D. 1995. Principles of graft versus leukemia reactivity. Bone Marrow Transplant. 1:61-68.

3. Barrett, A.J. 1997. Mechanisms of the graft-versus-leukemia reaction. Stem Cells. 15:248-258.

4. Barnes, D., Corp, M., Loutit, J., and Neal, F. 1956. Treatment of murine leukaemia with $\mathrm{x}$-rays and homologous bone marrow: preliminary communication. Br. Med. J. 2:626-630.

5. Horowitz, M.M., et al. 1990. Graft-verus-leukemia reactions after bone marrow transplantation. Blood. 75:555-562.

6. Apperley, J.F., Jones, L., Hale, G., and Goldman, J.M. 1986. Bone marrow transplantation for chronic myeloid leukemia: T-cell depletion with Campath-1 reduces the incidence of acute graft-versus-host disease but may increase the risk of leukemia relapse. Bone Marrow Transplant. 1:53-66.

7. Krenger, W., Hill, G.R., and Ferrara, J.L.M. 1997. Cytokine cascades in acute graft-versus-host disease. Transplantation. 64:553-558.

8. Kichian, K., Nestel, F.P., Kim, D., Ponka, P., and Lapp, W.S. 1996. IL-12 p40 messenger RNA expression in target organs during acute graft-versus-host disease. Possible involvement of IFN-gamma. J. Immunol. 157:2851-2856.

9. Nestel, F.P., Price, K.S., Seemayer, T.A., and Lapp, S.W. 1992. Macrophage priming and lipopolysaccharide-triggered release of tumor necrosis factor alpha during graft-versus-host disease. J. Exp. Med. 175:405-413.

10. Du, X., and Williams, D.A. 1997. Interleukin IL-11: review of molecular, cell biology, and clinical use. Blood. 11:3897-3908.

11. Du, X.X., Neben, T., Goldman, S., and Williams, D.A. 1993. Effects of recombinant human interleukin-11 on hematopoietic reconstitution in transplant mice: acceleration of recovery of peripheral blood neutrophils and platelets. Blood. 81:27-34.

12. Tepler, I., et al. 1996. A randomized placebo-controlled trial of recombinant human interleukin-11 in cancer patients with severe thrombocytopenia due to chemotherapy. Blood. 87:3607-3614.

13. Qui, B.S., Pfieffer, C.J., and Keith, J.C. 1996. Protection by recombinant interleukin-11 against experimental TNB-induced colitis. Dig. Dis. Sci. 41:1625-1630.

14. Trepicchio, W.L., Bozza, M., Pedneault, G., and Dorner, A.J. 1996. Recombinant human IL-11 attenuates the inflammatory response through down-regulation of proinflammatory cytokine release and nitric oxide production. J. Immunol. 157:3627-3634.

15. Trepicchio, W.L., Wang, L., Bozza, M., and Dorner, A.J. 1997. Interleukin11 regulates macrophage effector function through the inhibition of 
NF-kB. J. Immunol. 159:5661-5671.

16. Hill, G.R., et al. 1998. Interleukin-11 promotes $\mathrm{T}$ cell polarization and prevents acute graft-versus-host disease after allogeneic bone marrow transplantation. J. Clin. Invest. 102:115-123.

17. Morse, H.C., Shen, F.W., and Hammerling, U. 1987. Genetic nomenclature for loci controlling mouse lymphocyte antigens. Immunogenetics. 25:71-78.

18. Cooke, K.R., et al. 1996. An experimental model of idiopathic pneumonia syndrome after bone marrow transplantation. I. The roles of minor $\mathrm{H}$ antigens and endotoxin. Blood. 88:3230-3239.

19. Paul, S.R., Barut, B.A., Bennett, F., Cochran, M.A., and Anderson, K.C. 1992. Lack of a role of interleukin-11 in the growth of multiple myeloma. Leuk. Res. 16:247-252.

20. Matulonis, U., Salgia, R., Okuda, K., Druker, B., and Griffin, J.D. 1993. Interleukin-3 and p $210 \mathrm{bcr} / \mathrm{abl}$ activate both unique and overlapping pathways of signal transduction in a factor-dependent myeloid cell line. Exp. Hematol. 21:1460-1466.

21. Kappler, J., White, J., Wegmann, D., Mustain, E., and Marrack, P. 1982. Antigen presentation by Ia $\mathrm{B}$ cell hybridomas to $\mathrm{H}$-2-restricted $\mathrm{T}$ cell hybridomas. Proc. Natl. Acad. Sci. USA. 79:3604-3607.

22. Korngold, R., and Sprent, J. 1985. Surface markers of T cells causing lethal graft-vs-host disease to class I vs. class II H-2 differences. $J$. Immunol. 135:3004-3010.

23. Antin, J.H., and Ferrara, J.L.M. 1992. Cytokine dysregulation and acute graft-versus-host disease. Blood. 80:2964-2968.

24. Pietryga, D.W., Blazar, B.R., Soderling, C.C., and Vallera, D.A. 1987. The effect of $\mathrm{T}$ subset depletion on the incidence of lethal graft-versus-host disease in a murine major-histocompatibility-complex-mismatched transplantation system. Transplantation. 43:442-445.

25. Sprent, J., Schaefer, M., Gao, E.K., and Korngold, R. 1988. Role of T-cell subsets in lethal graft-versus-host disease (GVHD) directed to class I versus class II H-2 different hosts. J. Exp. Med. 167:556-569.

26. Sykes, M., Abraham, V.S., Harty, M.W., and Pearson, D.A. 1993. IL-2 reduces graft-versus-host disease and preserves a graft-versus-leukemia effect by selectively inhibiting CD4+ T cell activity. J. Immunol. 150:197-205.

27. Yang, Y., et al. 1997. Interleukin-12 preserves the graft-versus-leukemia effect of allogeneic CD8 T cells while inhibiting CD4-dependent graftversus-host disease in mice. Blood. 90:4651-4660.

28. Faber, L.M., van Luxemburg-Heijs, W.S., Veenhof, A.F., Willemze, R., and Falkenburg, J.H. 1995. Generation of CD4+ cytotoxic T-lymphocyte clones from a patient with severe graft-versus-host disease after allogeneic bone marrow transplantation: implications for graft-versusleukemia reactivity. Blood. 86:2821-2828.

29. Graubert, T.A., DiPersio, J.F., Russell, J.H., and Ley, T.J. 1997. Perforin/granzyme-dependent and independent mechanisms are both important for the development of graft-versus-host disease after murine bone marrow transplantation. J. Clin. Invest. 100:904-911.

30. Hill, G.R., et al. 1997. Total body irradiation and acute graft versus host disease. The role of gastrointestinal damage and inflammatory cytokines. Blood. 90:3204-3213.

31. Wiley, S.R., et al. 1995. Identification and characterization of a new member of the TNF family that induces apoptosis. Immunity. 3:673-682.
32. Snell, V., et al. 1997. Activity of TNF-related apoptosis-inducing ligand (TRAIL) in haematological malignancies. Br. J. Haematol. 99:618-624.

33. Kayagaki, N., et al. 1999. Involvement of TNF-related apoptosis-inducing ligand in human CD4+ T cell-mediated cytotoxicity. J. Immunol. 162:2639-2647.

34. Sykes, M., Harty, M.W., Szot, G.L., and Pearson, D.A. 1994. Interleukin2 inhibits graft-versus-host disease-promoting activity of $\mathrm{CD}^{+}$cells while preserving CD4- and CD8-mediated graft-versus-leukemia effects. Blood. 83:2560-2569.

35. Lichtenheld, M.G., et al. 1988. Structure and function of human perforin. Nature. 335:448-451.

36. Kägi, D., et al. 1994. Cytotoxicity mediated by $\mathrm{T}$ cells and natural killer cells is greatly impaired in perforin-deficient mice. Nature. 369:31-37.

37. Stalder, T., Hahn, S., and Erb, P. 1994. Fas antigen is the major target molecule for $\mathrm{CD}^{+} \mathrm{T}$ cell-mediated cytotoxicity. J. Immunol. 152:1127-1133.

38. Ju, S.T., Cui, H., Panka, D.J., Ettinger, R., and Marshak-Rothstein, A. 1994. Participation of target Fas protein in apoptosis pathway induced by CD4+ Th1 and CD8+ cytotoxic T cells. Proc. Natl. Acad. Sci. USA. 91:4185-4189.

39. Lowin, B., Hahne, M., Mattmann, C., and Tschopp, J. 1994. Cytolytic Tcell cytotoxicity is mediated through perforin and Fas lytic pathways. Nature. 370:650-652.

40. Suda, T., et al. 1995. Expression of the Fas ligand in cells of T cell lineage. J. Immunol. 154:3806-3813.

41. Lee, R.K., Spielman, J., Zhao, D.Y., Olsen, K.J., and Podack, E.R. 1996. Perforin, Fas ligand, and tumor necrosis factor are the major cytotoxic molecules used by lymphokine-activated killer cells. J. Immunol. 157:1919-1925.

42. Graubert, T.A., Russell, J.H., and Ley, T. 1996. The role of granzyme B in murine models of acute graft-versus-host disease and graft rejection. Blood. 87:1232-1237.

43. Blazar, B.R., Taylor, P.A. and Vallera, D.A. 1997. CD4 ${ }^{+}$and $\mathrm{CD}^{+} \mathrm{T}$ cells each can use a perforin-dependent pathway to mediate lethal graft-versus-host disease in major histocompatibility complex-disparate recipients. Transplantation. 64:571-576.

44. Hattori, K., et al. 1998. Differential effects of anti-Fas ligand and antitumor necrosis factor-a antibodies on acute graft-versus-host disease pathologies. Blood. 91:4051-4055.

45. Tsukada, N., Kobata, T., Aizawa, Y., Yagita, H., and Okumura, K. 1999. Graft-versus-leukemia effect and graft-versus-host disease can be differentiated by cytotoxic mechanisms in a murine model of allogeneic bone marrow transplantation. Blood. 93:2738-2747.

46. Shima, Y., et al. 1995. Myeloma cells express Fas antigen/APO-1 (CD95) but only some are sensitive to anti-Fas antibody resulting in apoptosis. Blood. 85:757-764.

47. van den Broek, M.F., et al. 1996. Decreased tumor surveillance in perforin-deficient mice. J. Exp. Med. 184:1781-1790.

48. Owen-Schaub, L.B., Radinsky, R., Kruzel, E., Berry, K., and Yonehara, S. 1994. Anti-Fas on nonhematopoietic tumors: levels of Fas/Apo-1 and bcl2 are not predictive of biological responsiveness. Cancer Res. 54:1580-1586.

49. Keane, M.M., Ettenberg, S.A., Lowery, G.A., Russell, S., and Lipkowicz, S. 1996. Fas expression and function in normal and malignant breast cell lines. Cancer Res. 56:4791-4798. 